\title{
Pars Plana Vitrectomy for Resistant Cystoid Macular Edema
}

\author{
Furqan Ahmed Khan ${ }^{1}$ and Naveed Ahmed Qureshi² \\ ${ }^{1}$ Department of Ophthalmology, Islamabad Medical \& Dental College, Islamabad, Pakistan \\ 2Department of Ophthalmology, Al-Shifa Trust Eye Hospital, Rawalpindi, Pakistan
}

\begin{abstract}
Objective: To evaluate the results of pars plana vitrectomy for cystoid macular edema (CME) resistant to medical treatment. Study Design: Quasi-experimental study

Place and Duration of Study: Al-Shifa Trust Eye Hospital, Rawalpindi, from January to July 2019.

Methodology: This study recruited 30 eyes of 30 patients with cystoid macular edema confirmed on optical coherence tomography that was refractory to medical treatment. Eyes with diabetic fibrous proliferation, optic atrophy, neo-vascular glaucoma, membrance and macular retinal pigment epithelial atrophy were excluded from the study. All patients underwent $23 \mathrm{G}$ pars plana vitrectomy followed by epiretinal membrane / internal limiting membrane (ERM/ILM) peeling and gas injection. In 11 eyes, perfluoropropane gas was injected; while in 19 eyes, sulfurhexafluoride gas was injected. Main outcome measures included pre- and post-op Snellen's visual acuity and central macular thickness (CMT). All patients completed their follow-up of six months.

Results: Mean age of 16 male and 14 female patients was $54.30 \pm 3.70$ years. Postoperative Snellen's visual acuity improved to $0.61 \pm 0.08$ from $0.11 \pm 0.04$ and postoperative central macular thickness improved to $223.80 \pm 40.20 \mu \mathrm{m}$ from $578.00 \pm 26.57 \mu \mathrm{m}$. Both differences were statistically significant $(p<0.001)$.

Conclusion: Pars plana vitrectomy with ERM / ILM peel and gas injection for CME refractory to medical treatment is an effective treatment. There was significantly improved best corrected visual acuity (BCVA) postoperatively along with decreased CMT on optical coherance tomography (OCT).
\end{abstract}

Key Words: Cystoid macular edema, Pars plana vitrectomy, Optical coherence tomography.

How to cite this article: Khan FA, Qureshi NA. Pars plana vitrectomy for resistant cystoid macular edema. J Coll Physicians Surg Pak 2019; 29(12):1165-1168.

\section{INTRODUCTION}

Cystoid macular edema (CME) is one of the prime causes of vision loss due to retinal vascular disease. It is an increase in the thickness of the macula due to a disturbance of the blood-retinal barrier causing fluid accumulation mainly in the outer plexiform layer (OPL). Specifically, vitreo-macular traction (VMT) is frequently found to result in CME. Traction at the Muller cells causes strain and the blood retinal barrier collapses resulting in dissociation of retina and RPE, consequently leakage and edema. ${ }^{1}$

Common causes of CME are diabetes, pars plana uveitis, retinitis pigmentosa, Irvine gas syndrome, laser photocoagulation, intraocular pressure lowering procedures, and certain drugs like prostaglandin E2 analogues. ${ }^{2}$ Most cases resolve within four months. If CME persist longer than that, then intervention is required. Medical treatment includes use of non-steroidal anti-inflammatory drugs, corticosteroids, carbonic anhydrase inhibitors, anti-

Correspondence to: Dr. Furqan Ahmed Khan, Department of Ophthalmology, Islamabad Medical \& Dental College.

Islamabad. Pakistan

E-mail:drfurqankhan@gmail.com

Received: September 04, 2019; Revised: November 20, 2019;

Accepted: November 29, 2019 vascular endothelial growth factors and chemical vitreolysis agents. ${ }^{3}$

Despite pharmacotherapy, a high number of patients continue to have persistent CME, which is considered resistant. An alternative option is pars plana vitrectomy (PPV) and removal of the posterior hyaloid as it decreases macular edema by relieving VMT. 4

The present study was conducted to evaluate the surgical outcomes of pars plana vitrectomy with ILM / ERM peel and gas injection in terms of Snellen's chart visual acuity and OCT-based central macular thickness, respectively.

\section{METHODOLOGY}

This was a quasi-experimental study conducted at the Vitreo-Retina Department, Al-Shifa Trust Eye Hospital, Rawalpindi, from January to July 2019. Ethical approval was taken from the Institute's Research Ethical Committee (REC). Informed consents were taken from all the patients included in this study. Thirty eyes of 30 patients were included in the study. The sample size was calculated using the University of California San Francisco (UCSF) Clinical \& Translational Science Institute paired T-test (before-after study) sample size calculator. ${ }^{5}$ Threshold for type 1 error (alpha) was kept at 0.05 , for type II error (beta) the rate was 0.20 , effect size was kept at 0.1 ; while standard deviation in the outcome (visual acuity 
outcome at 6 months) was taken as 0.17 from published literature. 6 The calculated sample size was 23 . One eye of patients 18 years or older with central macular thickness greater than 300 micrometers $(\mu \mathrm{m})$ which was refractory to medical treatment were included in the study. Refractory to medical treatment was defined as a persistent central macular thickness of $300 \mu \mathrm{m}$ or more after 3 intra-vitreal injections of bevacizumab spaced 4 weeks apart and subsequent one intra-vitreal injection of triamcinolone acetate. Eyes with neo-vascular glaucoma, optic atrophy, proliferative diabetic retinopathy with fibrous band proliferation threatening to cause a traction macular detachment and retinal pigment epithelium disturbances in macular region were excluded from the study.

After concise history, detailed ophthalmic evaluation was performed which included visual acuity examination (both unaided and best corrected), visual field examination by confrontation method, pupillary examination to rule out relative afferant pupillary defect (RAPD), Amsler grid test, anterior segment examination through slit lamp for any signs of uveitis and cataract, intraocular pressure measurement by Goldman applanation tonometer. Fundus examination was done by using $66 \mathrm{D}$ high magnification lens and $90 \mathrm{D}$ super-field lens for the vitreous cells, posterior hyaloids phase, epiretinal membrane formation, macular thickening, vitreous traction, posterior uveitis signs like vascular sheathing, and signs of diabetic retinopathy. The patients were examined through indirect ophthalmoscopy using $20 \mathrm{D}$ lens to rule out peripheral breaks and snow ball opacities and areas of vitreous traction. The patients were thoroughly investigated by performing OCT macula and wide field imaging to assess the central macular thickness and thickening of the epiretinal membrane. The patients were thoroughly counselled regarding the refractive nature of their disease and possible surgical treatment.

23-G PPV with ERM/ILM peel with gas injection was performed. In 11 eyes, perfluoropropane (C3F8) was injected; whereas sulfurhexafluoride (SF6) was injected in 19 eyes. Six-month follow-up was maintained with BCVA and CMT and was noted on subsequent follow-ups.

Patient's age, gender, best corrected pre- and postoperative Snellen's visual acuity, pre- and post- operative OCT-based macular thickness and cause of CME were entered into the database. Patient's age, pre- and postoperative Snellen's visual acuity (in decimal notation) as well as macular thickness were reported as mean with standard deviation. Patient's gender was reported as frequency and percentage. All post-operative data was obtained at 6-month follow-up. Paired sample t-test was used to ascertain a statically significant change in postoperative visual acuity as well as macular thickness. A $p$-value of $\leq 0.05$ was taken to be statistically significant.

\section{RESULTS}

A total of 30 eyes of 30 patients were included in the study $(n=30)$. Of these, 16 eyes were that of male patients $(53.3 \%)$; while 14 eyes were of female patients $(46.7 \%)$. All eyes were pseudophakic. The mean age of patients was $54.3 \pm 3.70$ years. Fifteen eyes had CME secondary to diabetic retinopathy, 10 had CME secondary to Uveitis; while two patients had Irvine-Gass syndrome and three developed CME after retinal cryopexy. The best corrected mean Snellen's preoperative visual acuity was $0.11 \pm 0.04$; while mean preoperative central macular thickness was $578.00 \pm 26.57$ $\mu \mathrm{m}$. The mean best corrected Snellen's postoperative visual acuity improved to $0.61 \pm 0.08$ and mean postoperative central macular thickness reduced to 223.80 $\pm 40.20 \mu \mathrm{m}$. All postoperative data were collected at end of 6-month follow-up. This information is depicted in Table I.

Table I: Pre- and post-operative visual acuity and central macular thickness comparisons.

\begin{tabular}{|c|c|c|}
\hline Parameter & Mean $\pm S D$ & Significance \\
\hline $\begin{array}{l}\text { Preoperative best corrected Snellen's } \\
\text { visual acuity (decimal notation) }\end{array}$ & $0.11 \pm 0.04$ & \multirow[t]{2}{*}{$p=0.000$} \\
\hline $\begin{array}{l}\text { Postoperative best corrected Snellen's } \\
\text { visual acuity (decimal notation) at } 6 \text { months }\end{array}$ & $0.61 \pm 0.08$ & \\
\hline Preoperative central macular thickness & $578.00 \pm 26.57 \mu \mathrm{m}$ & \multirow[t]{2}{*}{$p=0.000$} \\
\hline $\begin{array}{l}\text { Postoperative central macular thickness } \\
\text { at } 6 \text { months }\end{array}$ & $223.80 \pm 40.20 \mu \mathrm{m}$ & \\
\hline
\end{tabular}

There was a statistically significant difference between best corrected mean pre- and postoperative Snellen's visual acuity $(p<0.001)$. Similarly, there was a statistically significant difference $(p<0.001)$ between preoperative CMT and postoperative CMT.

\section{DISCUSSION}

CME is a complication that develops as a result of various diseases affecting the inner or outer blood retina barrier. Disturbance of the retinal capillaries comprising the blood retinal barrier, leakage of fluid in retina, along with posterior hyaloid traction are responsible for CME formation. ${ }^{7}$

The ILM serves as a platform for aggregating astrocytes. ${ }^{8}$ Peeling it not only absolves the traction, but also inhibits the fibrous astrocytes from reaccumulating on the retina. ${ }^{9}$

Lewis et al. reported that vitrectomy was effective for treating diabetic macular edema with a taut posterior hyaloid unresponsive to laser treatment. Nine eyes with diabetic CME underwent vitrectomy 3 to 35 months (mean=12 months) before ILM removal. Resolution of the CME was not attained after the first vitreous surgery in any of these cases. Subsequently, ILM was removed. In all the nine eyes, CME resolved after ILM removal, and visual acuity improved.

Regarding improvement of visual acuity, eyes that underwent initial combined vitrectomy and ILM peel had 
better visual outcomes, 8 of 12 achieved a visual acuity of better than 20/50 than did eyes that had previous vitrectomy without ILM peel. $10 \mathrm{~A}$ similar observation was reported by Harbour et al. $11 \mathrm{~A}$ shorter interval from the onset of CME to vitrectomy and ILM removal resulted in marked improvement in visual acuity.

Gandorfer et al. removed the ILM in 10 eyes that initially underwent vitrectomy and two that had previous vitrectomy; and Stefaniotou et al. performed initial vitrectomy and ILM removal on 55 eyes. Visual acuity improved in 11 eyes (92\%) and 38 eyes (69\%), respectively; and macular edema resolved in all eyes and 43 eyes (78\%), respectively, as seen by fluorescein angiography or biomicroscopy.12,13 However, these investigators did not analyse OCT findings. The detailed anatomic status of the macular edema was not available.

CME is also one of the important complications of uveitis and has a tendency to persist despite satisfactory control of the uveitis. ${ }^{14,15}$ A randomised pilot study (23 eyes) showed that PPV was more advantageous in terms of visual acuity and angiographic findings compared to a weaker effect of systemic treatment with steroids and immunosuppressants. However, the effect of ILM peeling was not assessed in uveitis. ${ }^{16,17}$

VMT syndrome occurs when an incomplete posterior vitreous detachment leads to a lingering traction of the vitreous at the macula, resulting in CME. In a review to estimate efficacy of PPV for VMT, approximately onethird out of 259 eyes gained 2 Snellen's lines. Eyes gained an average $0.25 \log M A R$, which approximates to just less than 2 Snellen's lines. 18

The results of this study were very similar, and all studies suggest the efficacy of ILM removal in the treatment of diabetic macular edema. To our knowledge, this is the first local report showing prompt resolution of CME in eyes that had undergone previous vitrectomy. Our study is limited by short-term follow-up and the lack of a control group; hence, the beneficial effect of PPV could not be compared with the natural disease course. Particularly, we could not exclude the effect of vitrectomy itself in assessing clinical results, as we did not perform the comparison with patients who received vitrectomy without ILM peel. Variability among disease subjects and their specific preoperative management (ocular medications received) was also not considered.

\section{CONCLUSION}

PPV with ILM / ERM peel and gas injection for CMOresistant to medical treatment is a safe effective surgical procedure with favourable results, in terms of improvement in BCVA and decrease in macular thickness as documented by Snellen's visual acuity chart and OCT, respectively; thus, improving visual quality of life.

\section{ETHICAL APPROVAL:}

The approval for the study was taken from Ethical Review Committee of Al-Shifa Trust Eye Hospital, Rawalpindi prior to start of research (Reference No: ERC-30/AST-18).

\section{PATIENTS' CONSENT:}

Informed consents were taken from all patients prior to enrollment in the study.

\section{CONFLICT OF INTEREST:}

Authors declared no conflict of interest.

\section{AUTHORS' CONTRIBUTION:}

FAK: Conceived and designed study; collected, analysed and interpreted data; drafted manuscript.

NAQ: Planned and designed the work; data acquisition; revised it critically for important intellectual content; reviewed final draft.

\section{REFERENCES}

1. Mec-Slomska AE, Adamiec-Mroczek J, Kuzmicz E, MisiukHojio M. Intravitreal ocriplasmin: A breakthrough in the treatment of vitreomacular traction? Adv Clin Exp Med 2017; 26:527-31.

2. Laursen SB, Erichsen JH, Holm LM, Kessel L. Prevention of macular edema in patients with diabetes after cataract surgery. J Cataract Refract Surg 2019; 45:854-69.

3. Dysli M, Rückert R, Munk MR. Differentiation of underlying pathologies of macular edema using spectral domain optical coherence tomography (SD-OCT). Ocul Immunol Inflamm 2019; 27:474-83.

4. Yan F, Xia FJ, Jiang F, Yu HG. Visual and morphological outcomes of vitreomacular traction syndrome in retinitis pigmentosa treated by vitrectomy. Int J Ophthalmol 2018; 11 : 1411-15.

5. University of California San Francisco Clinical and Translational Science Institute. Sample size for before-after study (Paired T-test) [internet]. 2019. [cited 8th September 2019]. Available from: http://www.sample-size.net/sample-size-study-paired-ttest/

6. Kim KT, Jang JW, Kang SW, Chae JB, Cho K, Bae K. Vitrectomy combined with intraoperative dexamethasone implant for the management of refractory diabetic macular edema. Korean $\mathrm{J}$ Ophthalmol 2019; 33:249-58.

7. Wielders LH, Lambermont VA, Schouten JS, van den Biggelaar FJ, Worthy G, Simons RW, et al. Prevention of cystoid macular edema after cataract surgery in nondiabetic and diabetic patients: A systematic review and meta-analysis. Am J Ophthalmol 2015; 160:968-81.

8. Kimura T, Kiryu J, Nishiwaki H, Oh H, Suzuma K, Watanabe D, et al. Efficacy of surgical removal of the internal limiting membrane in diabetic cystoid macular edema. Retina 2005; 25:454-61.

9. Liu J, Chen Y, Wang S, Zhang X, Zhao P. Evaluating inner retinal dimples after inner limiting membrane removal using multimodal imaging of optical coherence tomography. BMC Ophthalmol 2018; 18:155. 
10. Lewis H, Abrams GW, Blumenkranz MS, Campo RV. Vitrectomy for diabetic macular traction and edema associated with posterior hyaloidal traction. Ophthalmology 1992; 99:753-59.

11. Harbour JW, Smiddy WE, Flynn HW Jr, Rubsamen PE. Vitrectomy for diabetic macular edema associated with a thickened and taut posterior hyaloid membrane. Am J Ophthalmol 1996; 121:405-13.

12. Gandorfer A, Messmer EM, Ulbig MW, Kampik A. Resolution of diabetic macular edema after surgical removal of the posterior hyaloid and the inner limiting membrane. Retina 2000; 20:126-33.

13. Stefaniotou M, Aspiotis M, Kalogeropoulos C. Vitrectomy results for diffuse diabetic macular edema with and without inner limiting membrane removal. Eur J Ophthalmol 2004; 14:137-43.

14. Koronis S, Stavrakas P, Balidis M, Kozeis N, Tranos PG. Update in treatment of uveitic macular edema. Drug Des Devel Ther 2019; 13:667-80.
15. Tallouzi MO, Moore DJ, Barry RJ, Calvert M, Mathers J, Murray PI, et al. The effectiveness of pharmacological agents for the treatment of uveitic macular edema (UMO): A systematic review. Ocul Immunol Inflamm 2019; 27:658-80.

16. Tranos P, Scott R, Zambarakji H, Ayliffe W, Pavesio C, Charteris DG. The effect of pars plana vitrectomy on cystoid macular oedema associated with chronic uveitis: A randomized, controlled pilot study. Br J Ophthalmol 2006; 90:1107-10.

17. Kianersi F, Rezaeian-Ramsheh A, Pourazizi M, Kianersi H. Intravitreal diclofenac for treatment of refractory uveitisassociated cystoid macular oedema: A before and after clinical study. Acta Ophthalmol 2018; 96:e355-60.

18. Jackson TL, Nicod E, Angelis A, Grimaccia F, Prevost AT, Simpson AR, et al. Pars plana vitrectomy for vitreomacular traction syndrome: A systematic review and metaanalysis of safety and efficacy. Retina 2013; 33:2012-7.

-............ 